http://jmscr.igmpublication.org/home/ ISSN (e)-2347-176x ISSN (p) 2455-0450 crossref DOI: https://dx.doi.org/10.18535/jmscr/v8i5.12

\title{
Analysis and follow up of shotgun injuries in pediatric age group
}

\author{
Authors \\ Dr Suraj S Horakeri ${ }^{1 *}$, Dr Mayank Dhir ${ }^{2}$, Dr Sagar Sinha ${ }^{3}$, Dr Dattatray Bhusare ${ }^{4}$ \\ ${ }^{1}$ First-year MD Resident, Emergency Medicine \\ ${ }^{2}$ Third-year MD Resident, Emergency Medicine \\ ${ }^{3}$ Assistant Professor, Emergency Medicine \\ ${ }^{4}$ Head of Department, Emergency Medicine
}

MGM Medical College and Hospital, Kamothe, Navi Mumbai, India, PIN 4102019

*Corresponding Author

Dr Suraj S Horakeri

MGM Medical College and Hospital, Navi Mumbai, Maharashtra, India

\begin{abstract}
Introduction: Maharashtra 'Bandh' call from the members of a community in the state of Maharashtra. The Maharashtra government has appealed to protesters to maintain calm and not break the law. A gathering of over 500 protestors in the city of Navi Mumbai got violent, especially on the major highway junction close to the hospital wherein the local law enforcement agencies had to use various methods including 'lathi-charge' and shotgun fire to control the escalating situation. Communication within hospital and even outside the hospital was getting difficult, internet was jammed and absolutely no means of transportation for staff inside hospital to go out and vise versa. Hospital had a limited resource to manage the victims of 'Bhand' (Short gun injury). To triage accordingly and manage the mob was challenge to take over.

Methodology: As a result of the above violence and response and resources available a total of 26 patients (including both civilians and police personnel) in which 3 were pediatric age group presented to this teaching tertiary care hospital in a span 12 hours. This study is a descriptive analysis of the same with emphasis on triage, resource allocation and outcomes.

Results

1. Disaster-management systems-of-care were activated and executed. All 26 patients were triaged initially, including 2 categorized red.

2. Total of 14 were discharged after initial care and 12 admitted for definitive care.

3. Out of the 12 admitted, 10 had sustained ballistic injuries. 3 of them were operated: 1 required major surgery and 2 minor surgeries. The remaining 7 were managed conservatively using combination of various criteria. 2 of the 12 patients required ICU admission and rest were managed in ED-Wards.

4. All patients were discharged home with no disability.

\section{Conclusions}

1. Effective triaging and systematic disaster-management protocol activation is the most important first step in dealing with such a situation.

2. Outcome was good because of a multi-disciplinary team approach.
\end{abstract}




\section{Introduction}

The Maharashtra government has appealed to protesters to maintain calm and not break the law. A gathering of over 500 protestors in the city of Navi Mumbai got violent, especially on the major highway junction close to the hospital wherein the local law enforcement agencies had to use various methods including 'lathi-charge' and shotgun fire to control the escalating situation. To triage accordingly and manage the mob and manage ballestic injury was challenge to take over.Gun violence: A common problem in certain western countries and disturbed regions in the world. India has largely been a peaceful state with only few areas dealing with these situations. Military personnel are used to handle these combat situations however exposure of most civilian doctors is rare. Ballistic injuries are less studied form of injury and very few research works exist on it especially in the pediatric age group.The extent of tissue/organ damage depends on a wide variety of factors including the bullet's diameter or caliber, as well as its shape, velocity, tumbling characteristics, and weight. Between $47 \%$ and $59 \%$ of shotgun wounds to the extremities are associated with major soft tissue injury. 59\% with nerve injury, $24 \%$ with vascular damage and $44 \%$ to $47 \%$ with bone or joint Injury ${ }^{1,2}$
Aims and Objectives

1. To highlight the ED management.

2. To analyse the additional pediatric principles with multi-disciplinary approach.

3. To study the follow-up and outcome of these patients.

\section{Methodology}

- Three pediatric patients presented to the Emergency Department (ED) of a tertiary care hospital as part of a mass-casualty with alleged gunshot injuries after a civil unrest situation.

- This study is a descriptive analysis of the same with emphasis on triage, initial assessment and management, multidisciplinary team approach and long-term outcomes over 6 months.

- Sample size -3

- Age less than 18 years part of shotgun injuries included in the study.

\section{Objective}

1. Analysis and management of shotgun injury.

2. Follow up and outcome of all ballestic injury children.

\section{Table no.1}

\begin{tabular}{|c|c|c|c|c|c|}
\hline Name & Age & Sex & $\begin{array}{l}\text { Ballestic injury } \\
\text { (major/minor) }\end{array}$ & Injuries & X-Ray \\
\hline A & 5 years & Male & Minor & $\begin{array}{l}\text { SGI }(1 \text { pellet)- Lt hand thumb } \\
, 1 \mathrm{X} 0.5 \mathrm{~cm} \text { abrassion ,Lt index } \\
\text { finger } 0.5 \times 0.5 \text { abrassion, } \\
\text { movement restriction of } \\
\text { forearm, lubricals }\end{array}$ & $\begin{array}{l}\text { FB at } 2 \text { MCP joint s/o foreign } \\
\text { body, vertical chip \# @ middle } \\
\text { phalnx of index finger }\end{array}$ \\
\hline B & 12 years & Female & Minor & $\begin{array}{l}\text { SGI(1 pellet)-Rt shoulder injury } \\
\text {,single pellet in Rt humeerus,Rt } \\
\text { shoulder abrassion 0.5.X O.5 } \\
\text { cm,no FND }\end{array}$ & $\begin{array}{l}\text { metallic radio opaque } \\
\text { foreign body in right humerus }\end{array}$ \\
\hline $\mathrm{C}$ & 18 years & Male & Minor & $\begin{array}{l}\text { SGI (1 pellet) Rt forearm - } \\
\text { abrassions on index, middle } \\
\text {,ring finger, Multiple SGI (6 } \\
\text { pellets) in the Rt thigh, I pellet } \\
\text { Rt leg }\end{array}$ & $\begin{array}{l}\text { metallic radio opaque } \\
\text { foreign body in right humerus } \\
2 \text { dense radio opaque density } \\
\text { in 3rd distal thigh anterio } \\
\text { lateral aspect, } 5 \text { radio opaque } \\
\text { FB in front of tibia. }\end{array}$ \\
\hline
\end{tabular}




\section{JMSCR Vol||08||Issue||05||Page 72-77||May}

A

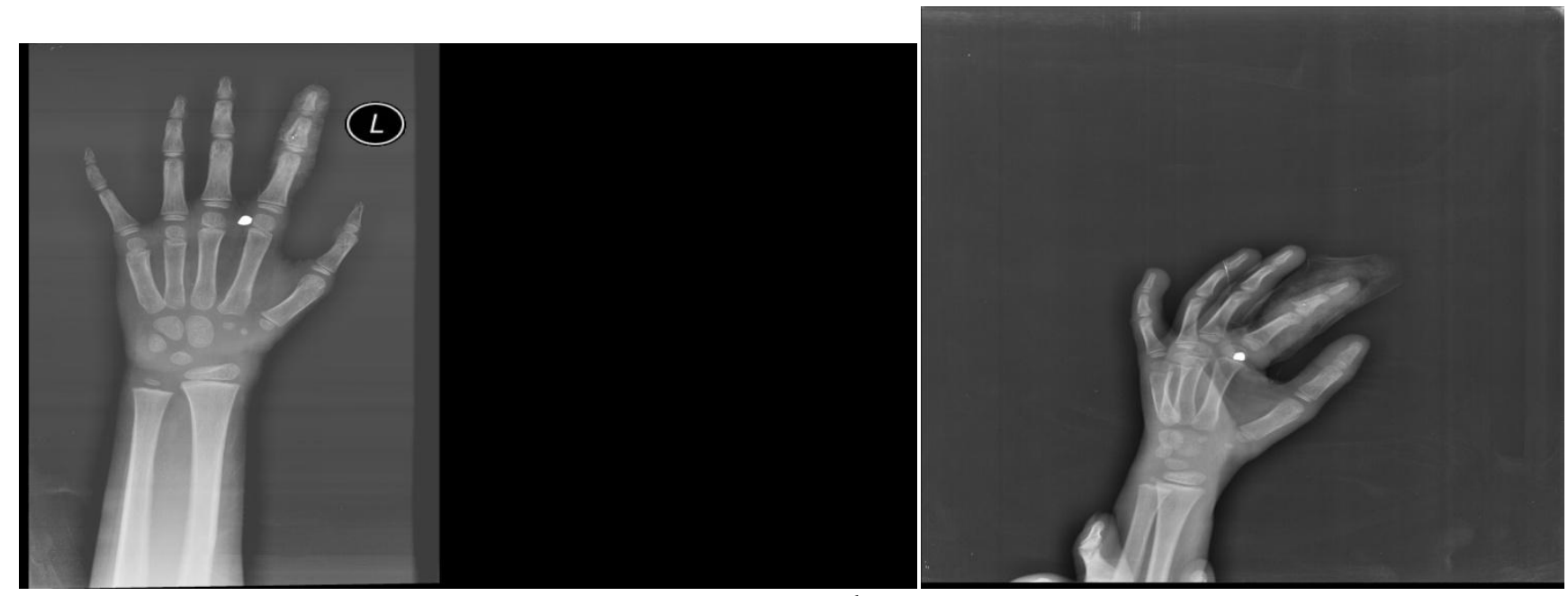

Fig. 1 Foreign body at $2^{\text {nd }}$ metacarpal joint

B

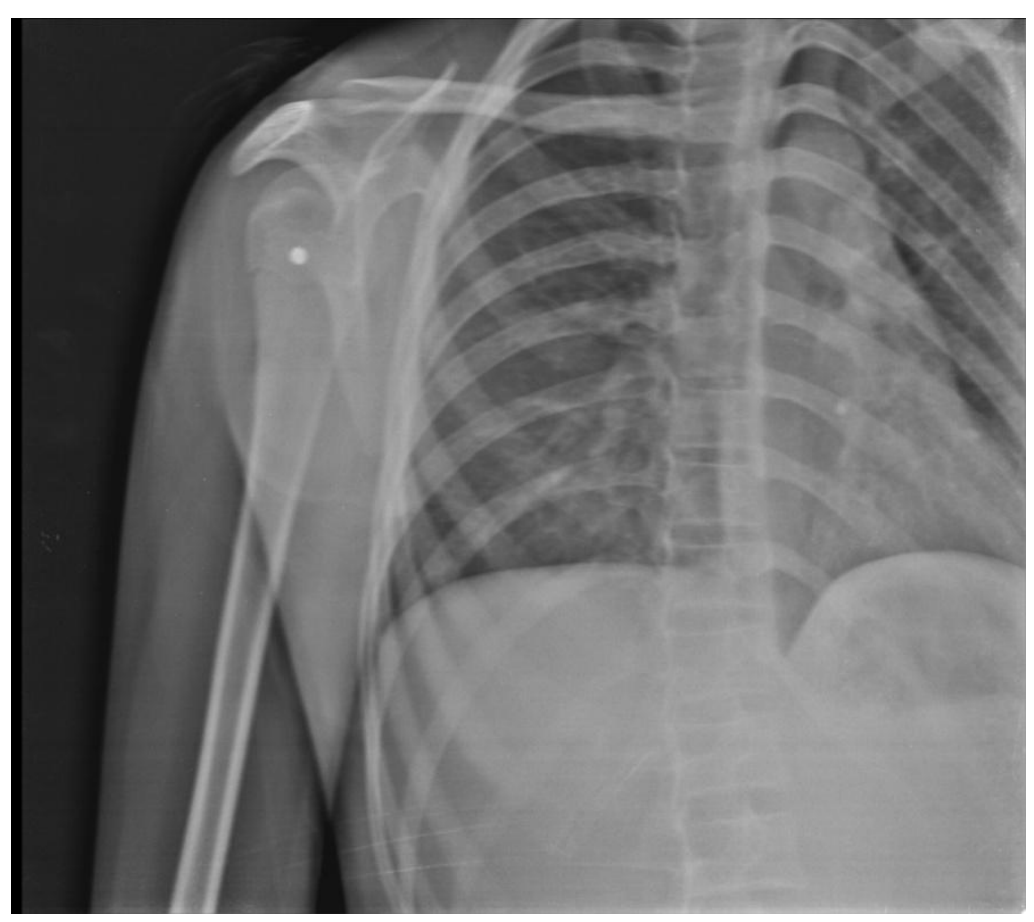

Fig.2 1 metallic radio opaque foreign body in right humerus 


\section{JMSCR Vol||08||Issue ||05||Page 72-77||May}

C
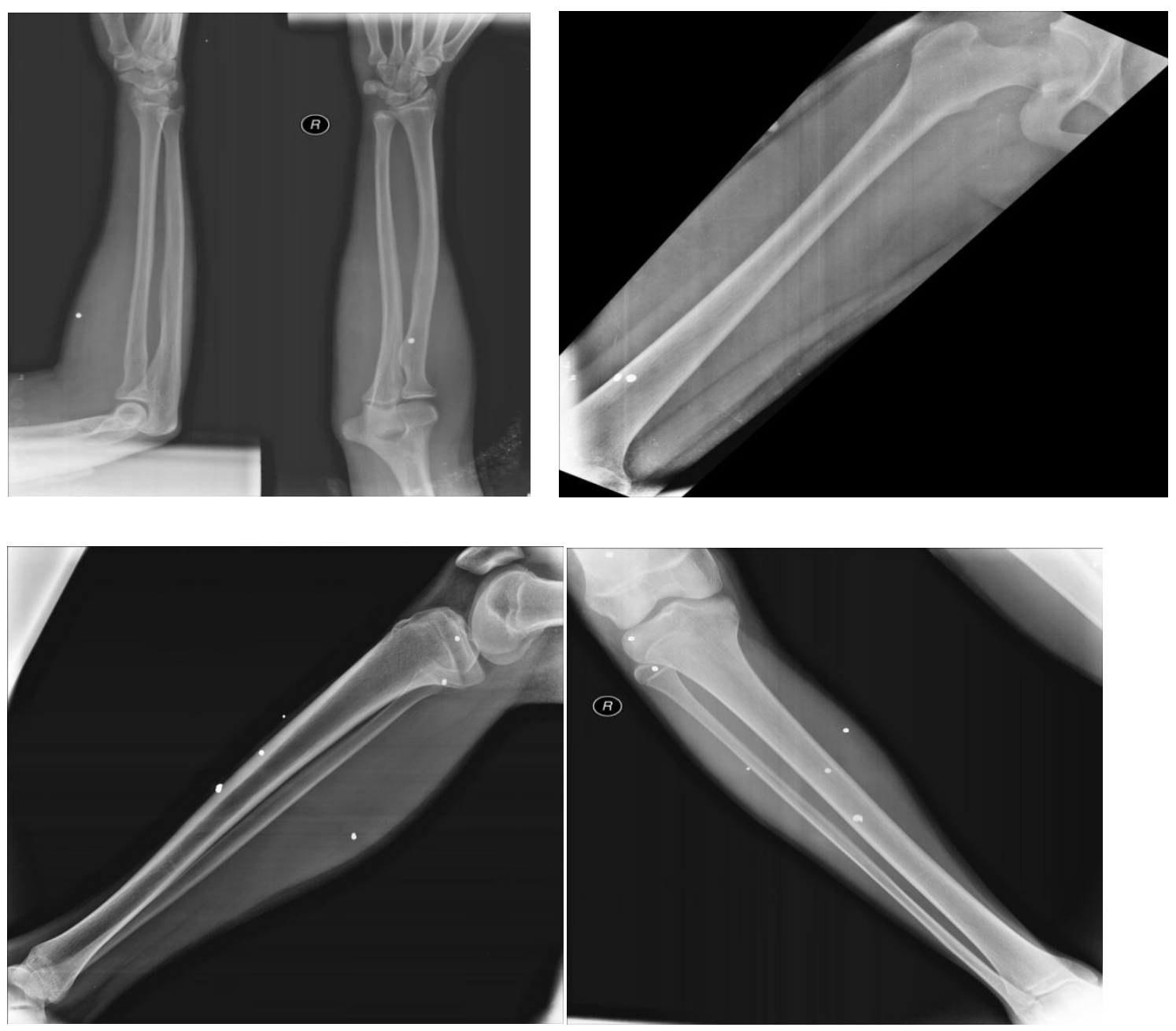

Fig. No 31 metallic radio opaque foreign body in right humerus.

2 dense radio opaque density in 3rd distal thigh anterio lateral aspect, 5 radio opaque FB in front of tibia.

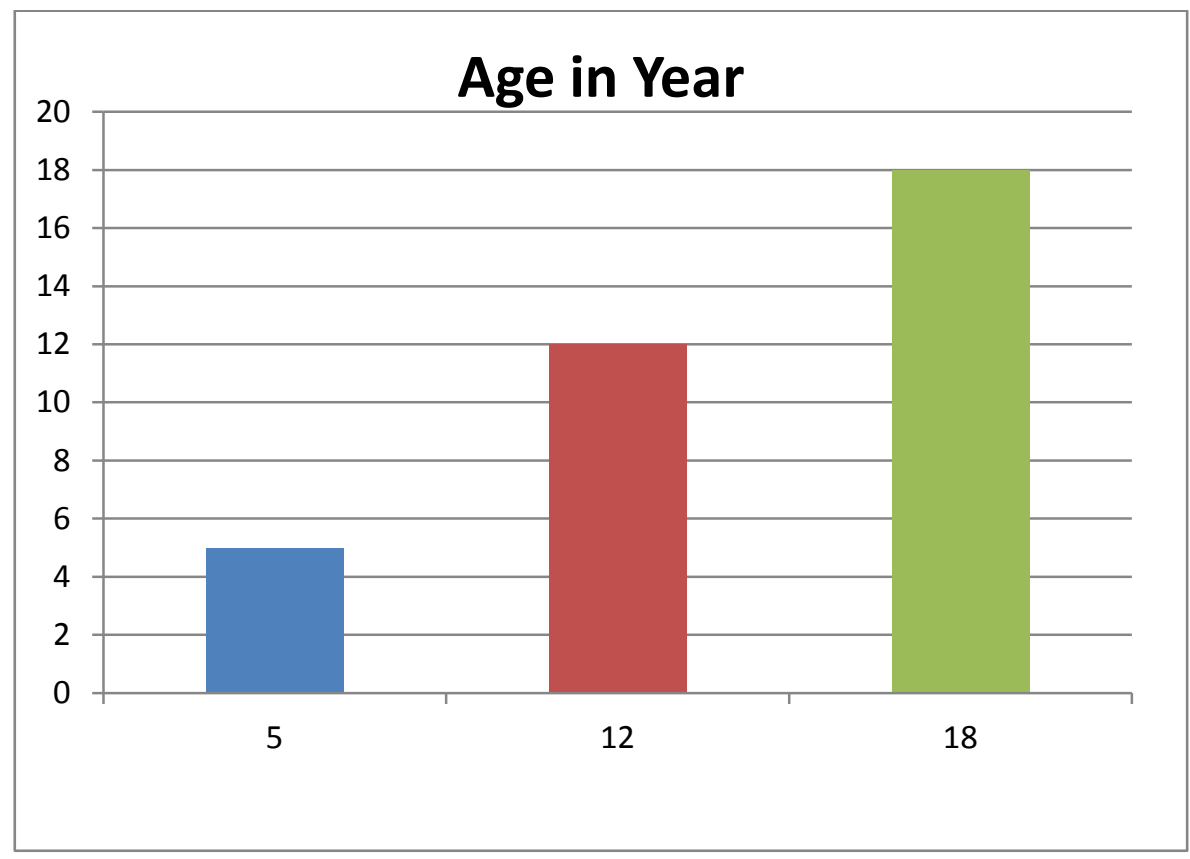

Fig. No.4 Age group 


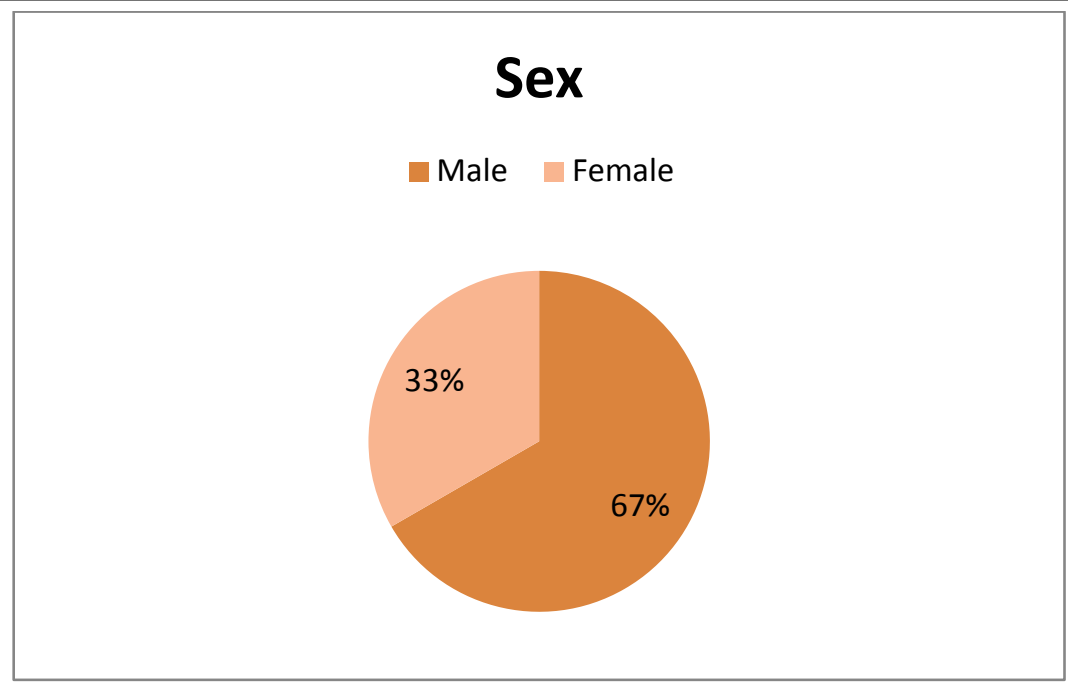

Fig. No.5 Sex

\section{Management}

- Disaster management protocol activated; patients triaged and initial management (wound care, fluids and analgesia) initiated for the 3 pediatric patients.

- Multidisciplinary approach: Assessment of neurovascular/organ injury, risk of wound infection and developmental factors for a child done.

- None of the patients required any surgical intervention; only supportive care continued.

- After antibiotic course: Daily dressing and good pain control.

- All patients discharged with no disability or deficit.

- 1 patient operated outside, for extraction of pellet; however complains of residual pain on subsequent follow up.

- History of trauma reveals that all 3 children were at home and were hit by stray fire from the incident site.

\section{Results}

Table no.2

\begin{tabular}{|l|c|c|}
\hline Names & Outcome & Outcome \\
\hline A & Good & 6 months \\
\hline B & Good & $\begin{array}{c}\text { Good (no deficit but residual } \\
\text { pain due to intervention) }\end{array}$ \\
\hline C & Good & Good(no deficit) \\
\hline
\end{tabular}

\section{Conclusion}

1. Initial ED triage, assessment and initial care are crucial as a first-step in pediatric ballistic injury.

2. Multidisciplinary approach is crucial to determine surgical vs conservative care.

3. Pellet removal procedure should be considered only in complicated cases after risk/benefit consideration.

4. Any firing in a civilian area can lead to unintended collateral injury.

\section{Discussion}

- Indications for intervention of gunshot wounds :

(1) injuries with significant soft tissue deficit

(2) significant bone loss

(3) vascular injury

(4) severe contamination

(5) injuries that are at risk for amputation and that require multiple dedridements

(6) comminuted fractures too proximal or distal for intramedullary nailing ${ }^{3}$.

\section{Results}

1) Disaster-management systems-of-care were activated and executed. All 26 patients were triaged initially of which 3 were pediatric age.

2) All 3 were discharged after primary assessment and management. 
3) All patients were followed up and analysed with no disability and had a good outcome.

\section{Conclusions}

1) Systematic disaster-management is the most important first step in dealing with such a situation.

2) Outcome was good because of a multidisciplinary team approach.

I confirm the originality of the research work and that all fellow authors/researchers of this research work are aware and in agreement with this abstract submission.

\section{References}

1. Ferraro SP Jr, Zinar DM. Management of gunshot fractures of the tibia. Orthop Clin North Am. 1995 Jan;26(1):181-9.

2. Deitch EA, Grimes WR. Experience with 112 gunshot wounds of the extremities. J Trauma. 1984 Jul;24:600-3.

3. Luce EA, Griffen WO. Shotgun injuries of the upper extremity.J Trauma. 1978;18: 487-92. 